\title{
The effects of electroconvulsive shock on extinction*
}

\author{
G. L. DEMPSEY and A. GRANT YOUNG \\ Louisiana State University, Baton Rouge, La. 70803
}

Seventy-two naive male albino rats were trained to leverpress for sucrose using a discrete trial procedure. The Ss were trained on a continuous reinforcement schedule, a fixed-, or a variable-ratio schedule. Following acquisition, for one-third of the Ss in each group, a leverpress produced an ECS; for the other two groups, which served as controls, no treatment was given. All groups were extinguished $24 \mathrm{~h}$ later. Immediately following this extinction session, one control group experienced ECS, and $24 \mathrm{~h}$ later all Ss were subjected to a second extinction session. Results showed that ECS maintained responding and prolonged extinction. Results further showed no loss of the partial reinforcement effect.

When electroconvulsive shock (ECS) is administered shortly after a learning experience, the result appears to be retrograde amnesia (RA) for that learning experience (Lewis, 1969). This apparent disruption of recent memory is usually explained in terms of a theory which suggests that time is required, following sensory input, for a memory trace to become permanently fixed. If head trauma, such as ECS, is experienced during this period of fixation, the consolidation or fixating process is disrupted and the memory trace is thereby lost (McGaugh, 1966).

Several recent studies, however, have produced findings which suggest that the primary effect of ECS is one of hyperirritability, or increased drive level, manifested in an inflated rate of responding (Young \& Galluscio, 1970; Young \& Day, 1970; Young \& Day, 1971). For example, Young and Costelloe ${ }^{1}$ trained rats to leverpress on a continuous reinforcement schedule (CRF), a fixed-ratio schedule (FR), or a variable-ratio schedule (VR). Following acquisition, half of the Ss in each group experienced ECS and then all Ss were extinguished. Results showed an inflated response rate during extinction for ECS-treated Ss. These findings are in agreement with those which have shown that operant responding and free open-field activity were increased by ECS (Routtenberg \& Kay, 1965) and that shuttlebox performance was enhanced by ECS (Vanderwolf, 1963).

If, as these studies suggest, ECS produces an inflated rate or perseveration of responding, it ought to be possible to show that ECS will facilitate, maintain, or prolong a response both before and after extinction. The present experiment was designed to investigate this possibility.

*This research was supported in part by a grant from the University Council on Research, Louisiana State University, to the second author.

\section{METHOD \\ Subjects}

The Ss were 72 naive albino rats, $150-175 \mathrm{~g}$ in weight at the start of the experiment.

\section{Apparatus}

The apparatus consisted of two identical Lehigh Valley operant chambers, each enclosed in a sound-insulated ventilated cubicle. Each operant chamber had a grid floor; fitted on the end wali was a retractable lever and a liquid dipper, which dispensed $.01 \mathrm{ml}$ of a $40 \%$ sucrose solution used as reinforcement. All E-controlled events were operated by an electronic programming device.

Procedure

The Ss were selected randomly from the LSU colony, housed in individual cages, and placed on a 23-h food-deprivation schedule consisting of $10 \mathrm{~g}$ Purina lab chow. Water was available in the cages at all times, and Ss were given 4 days to adapt to the deprivation schedule and the home cage.

From Day 5 to Day 8, Ss were handled in groups of four for approximately $5 \mathrm{~min}$ daily. On Day 9 , Ss began magazine training on a VI 30-sec schedule. Experimental sessions consisted of 20 presentations of the dipper and continued for 4 days.

On Day 13, all Ss were conditioned to leverpress and were allowed to make 50 reinforced responses. On the following day, all Ss made 100 continuously reinforced responses. On Day 15 , Ss were divided randomly into three groups (CR, FR, and VR) and began acquisition training. For the CR group, acquisition was under a CRF schedule throughout the experiment. For the FR group, acquisition was under a FR-2 schedule for the first 5 days and under FR-3 for the last 5 days. The VR group was under a VR-2 schedule throughout the experiment.

All Ss made 100 leverpresses daily for 10 days. A discrete trial procedure was used and the lever, which required $4 \mathrm{sec}$ to retract and extend fully, was inoperative during retraction.

On the day following completion of acquisition, each group was subdivided randomly, resulting in the following nine groups $(\mathrm{N}=8)$.

Groups $\mathrm{CR}(\mathrm{XX}), \mathrm{VR}(\mathrm{XX})$, and $\mathrm{FR}(\mathrm{XX})$ : On treatment day, $S s$ in these groups made one nonreinforced leverpress. Twenty-four hours later, all Ss were subjected to an extinction session (X). Following this extinction session, the number of leverpresses made by each $\mathrm{S}$ was recorded, and all $\mathrm{Ss}$ were returned to their home cages. Twenty-four hours later, all Ss were extinguished for the second time $(\mathrm{X})$, and leverpresses were again recorded.

Groups CR(ECS/XX), VR(ECS/XX), FR(ECS/XX): On treatment day, $S s$ in these three groups were fitted with a harness. Fine wire from an ECS source, which entered the operant chamber from the top, was connected to the harness and from the harness to microalligator clips attached to S's ears. The harness permitted complete freedom of movement to all parts of the operant chamber. The first leverpress produced a $50-\mathrm{mA}$ 50-msec ECS, delivered through the earclip electrodes. The Ss were then returned to their home cages until $24 \mathrm{~h}$ later, when they were subjected to a first extinction session. Following this session, Ss were returned to their home cages, and $24 \mathrm{~h}$ later Ss were subjected to a second extinction session.

Groups CR(X/ECS/X), VR(X/ECS/X), FR(X/ECS/X): For Ss in these three groups, treatment prior to the first extinction session consisted of one nonreinforced leverpress. Twenty-four hours later these Ss were subjected to an extinction session. Immediately following this extinction session, Ss were removed 
Table 1

Mean Number of Leverpresses in Extinction

\begin{tabular}{lccr}
\hline Group & $\begin{array}{c}\text { Extinction } \\
\text { Session 1 }\end{array}$ & $\begin{array}{c}\text { Extinction } \\
\text { Session 2 }\end{array}$ & Total \\
\hline CR (XX) & 50.88 & 28.88 & 79.76 \\
CR (X/ECS/X) & 52.63 & 42.63 & 95.26 \\
CR (ECS/XX) & 62.00 & 39.75 & 101.75 \\
VR (XX) & 80.50 & 48.75 & 129.25 \\
VR (X/ECS/X) & 81.75 & 54.12 & 135.87 \\
VR (ECS/XX) & 85.00 & 43.75 & 128.75 \\
FR (XX) & 54.63 & 39.63 & 94.26 \\
FR (X/ECS/X) & 61.75 & 46.38 & 108.13 \\
FR (ECS/XX) & 64.88 & 45.25 & 110.13 \\
\hline
\end{tabular}

from the operant chamber, earclips were attached, and an ECS of the same intensity and duration described earlier was administered. The Ss then were returned to their home cages for $24 \mathrm{~h}$, after which they were again returned to the operant chamber for a second extinction session.

All extinction sessions were $10 \mathrm{~min}$ in length for all groups and, during extinction, stimulus conditions were the same as during acquisition, except that the dipper was inoperative.

\section{RESULTS}

The total number of responses made during each extinction session was recorded for each S. For the first extinction session, more responses were made by Group VR(ECS/XX), followed in order by Groups $\operatorname{VR}(X / E C S / X), \operatorname{VR}(X X), F R(E C S / X X), \operatorname{CR}(E C S / X X)$, FR(X/ECS/X), FR(XX), CR(X/ECS/X), and CR(XX). For the second extinction session, more responses were made by Group VR(X/ECS/X), followed in order by Groups VR(XX), FR(X/ECS/X), FR(ECS/XX), VR(ECS/XX), CR(X/ECS/X), CR(ECS/XX), FR(XX), and $C R(X X)$. These data were subjected to an analysis of variance which showed that the main effects of schedule and session were significant beyond the .01 level. The main effect of treatment was not significant at the .05 level. Group comparisons ( $t$ tests) for the schedule main effect showed that for Session 1 Groups CR(XX) vs $\mathrm{VR}(\mathrm{XX}), \mathrm{CR}(\mathrm{X} / \mathrm{ECS} / \mathrm{X})$ vs $\mathrm{VR}(\mathrm{X} / \mathrm{ECS} / \mathrm{X}), \mathrm{VR}(\mathrm{XX})$ vs FR(XX), and CR(ECS/XX) vs VR(ECS/XX) were significant beyond the .01 level; and the comparisons $\mathrm{VR}(\mathrm{X} / \mathrm{ECS} / \mathrm{X})$ vs $\mathrm{FR}(\mathrm{X} / \mathrm{ECS} / \mathrm{X})$ and $\mathrm{VR}(\mathrm{ECS} / \mathrm{XX})$ vs FR(ECS/XX) were significant beyond the .05 level.

For the second extinction session, only the comparison $\mathrm{CR}(\mathrm{XX})$ vs $\operatorname{VR}(\mathrm{XX})$ was significant beyond the .05 level.

Group comparisons for the session main effect showed a significant difference, beyond the .01 level, for Groups CR(ECS/XX), VR(XX), VR(X/ECS/X), VR(ECS/XX), CR(XX), FR(XX), FR(X/ECS/X), and FR(ECS/XX). The difference between the two extinction sessions for Group CR(X/ECS/X) was not significant at the .05 level.

The Schedule by Session interaction was significant beyond the .01 level, and these data were, therefore, subjected to an analysis of variance for simple effects. The results showed that for Session 1 comparisons $C R$ vs VR and FR vs VR were significant beyond the .01 level, while for Session 2 only the CR vs VR comparison was significant beyond the .05 level.

The mean number of responses in extinction for each group is shown in Table 1.

\section{DISCUSSION}

The finding that Ss which experienced ECS prior to the first extinction session made more responses during that session than their respective controls is consistent with earlier findings (i.e., Young and Costelloe). ${ }^{1}$ This, along with the finding that for the second extinction session, within schedules of reinforcement, a greater number of responses were made by Ss which experienced ECS prior to that session, suggests that ECS does, in fact, have a hyperactive effect-or in some way produces an increased drive level-resulting in an inflated rate of responding.

The most critical finding of this study is that the administration of ECS did maintain responding to such an extent that there was no significant difference between the two extinction sessions for Group $\mathrm{CR}(\mathrm{X} / \mathrm{ECS} / \mathrm{X})$. Additionally, within FR and VR groups, Ss which experienced ECS prior to the second extinction session made more responses during that session than did their respective controls. The fact that these differences did not reach significance may be due to the fact that these schedules of reinforcement normally produce a much higher rate of responding in extinction than does a CR schedule, which is characterized by a low rate of responding in extinction. Thus, any effect that would tend to increase responding in extinction would be more easily detected in CR-trained Ss.

Typically, if aversive stimulation follows a learned response, and if this aversive stimulation is shortly followed by ECS, the result appears to be RA for this one-trial learning. Similarly, in the present study, when ECS followed the first extinction session, the number of responses made during the second extinction session was greater than that made by the respective control Ss which did not experience ECS. This finding normally would be explained in terms of ECS-produced RA for the first extinction session. That this interpretation is not tenable is suggested by the fact that, when ECS preceded the first extinction session, the number of responses made during that session was also increased.

The finding that ECS failed to eliminate the partial reinforcement effect (PRE)-the greatly increased resistance to extinction shown by Ss trained on a partial reinforcement schedule-in the first extinction session is not in agreement with previous studies (i.e., Young \& Day, 1970) that have reported a loss of the PRE for VR-trained Ss which experienced footshock followed by ECS. This finding suggests a possible interaction between footshock and ECS and requires further investigation.

In summary, the findings of the present study suggest that the primary effect of ECS is not the production of RA but rather of hyperactivity or an increased drive level, that a memory consolidation hypothesis is not the proper explanation for the effects of ECS, and that the findings of many ECS studies that have been interpreted in terms of a memory consolidation hypothesis may not, in fact, be relevant to that hypothesis.

\section{REFERENCES}

Lewis, D. J. Sources of experimental amnesia. Psychological Review, 1969, 76, 461-472.

McGaugh, J. L. Time-dependent processes in memory storage. Science, 1966, 153, 1351-1358.

Routtenberg, A., \& Kay, K. E. Effects of one electroconvulsive shock seizure on rat behavior. Journal of Comparative \& Physiological Psychology, 1965, 59, 285-288.

Vanderwolf, C. H. Improved shuttle-box performance following ECS. Journal of Comparative \& Physiological Psychology, $1963,56,983-986$.

Young, A. G., \& Day, H. D. ECS effects following contınuous and partial reinforcement training. Psychonomic Science, 1970, 21, 131-132.

Young, A. G., \& Day, H. D. Effect of ECS on one-trial learning 
and on the partial reinforcement effect. Psychonomic Science, 1971, 24, 99-100.

Young, A. G., \& Galluscio, E. H. Effect of ECS on one-trial

learning following continuous and partial reinforcement learning following continuous and partial reir
NOTE

1. Young, A. G., and Costelloe, C. Unpublished manuscript, 1971. (Received for publication November 22, 1972.) 